\title{
Long-term changes in intellect and behaviour after hemispherectomy
}

\author{
HUW GRIFFITH AND MAY DAVIDSON
}

\begin{abstract}
From the Department of Neurological Surgery, Radcliffe Infirmary, Oxford, and The Warneford Hospital, Oxford
\end{abstract}

With the advent in the 1950 s of cerebral hemispherectomy for infantile hemiplegia, studies of short-term changes in intellect after this operation were sporadically reported, e.g., Cairns and Davidson (1951), Uecker, French, and Johnson (1954), and Munz and Tolor (1955), but no clear-cut picture of mental changes in measurable terms has been obtained. The brain-damaged and epileptic children who had the operations were often severely mentally retarded and suffered from behaviour disorders, so that, despite dramatic results in abolishing the fits and in improving the behaviour, objective changes in intellect due to operation were difficult to demonstrate. Many of the subjects were of an age when they could not be usefully tested before operation.

From 1950 to 1961 hemispherectomy for infantile hemiplegia with behaviour disorder and convulsions was carried out on 18 patients in the Department of Neurological Surgery at the Radcliffe Infirmary. Where possible psychological testing was performed before and after operation.

Three of the earlier patients in this series were reported in 1951 by Cairns and Davidson. The opportunity was taken in 1965 to review the surviving patients from this series. In addition to reporting the long-term results we have tried to show that the compensation of the remaining cerebral hemisphere for the side which was destroyed and subsequently removed may be less complete than has previously been recognized.

\section{CASE MATERIAL}

The 18 patients operated upon all survived the operation but three have since died after some years of a haemorrhagic complication of the operation (Oppenheimer and Griffith, 1966). A fourth patient has died of tuberose sclerosis, and a fifth of tuberculosis; neither of these children was suitable for psychometric testing at any stage. One patient, a Portuguese in whom difficulties of language hampered objective testing, cannot be traced. The remaining 12 were all seen personally by both authors in 1965, retested, and an assessment made of their social adjustment and behaviour. The period of follow-up extends from four to 15 years, with a mean of just over 10 years. It should be said that on the social side the patients and their families had the advantage of an extremely high level of skilled advice on educational and social matters, and it is probable that they would have done much less well had this not been available.

\section{METHODS}

In the earlier patients the revised Stanford-Binet tests were used pre-operatively, and in much of the later testing this has boen repeated where appropriate. The Wechsler Bellevue form 1 was used in some. The Wechsler intelligence scale for children was used for many of the later patients and the Wechsler adult intelligence scale for the older patients and for those who are now adults. The results from all the Wechsler tests were regarded as comparable in the same patient provided the scaled scores were converted into standard scores before comparisons were made. Where the behaviour disorder had been marked we have regarded the test scores with some caution. For instance, case 5 was easily irritated and fatiguable and was only able to complete the tests on one occasion. The intervals between tests were such as to minimize the practice effect.

Objective testing was not used from the beginning to assess the behaviour disorder of these patients. A retrospective assessment was undertaken independently by the two authors using a provisional five-point scale. We made use of the clinical notes, together with information from the patient, from relatives, and from nurses and doctors familiar with the patients.

0 Behaviour within normal limits.

1 Mild changes, e.g., excessive loquaciousness in adults or poor concentration in children.

2 Temper outbursts with some difficulty in home management, and more severe changes than (1).

3 Severe disorder, hyperactive, little power of relating to others, but manageable at home.

4 Institutionalized for behaviour disorder, more animal than child.

\section{RESULTS}

INTELLIGeNCE The scores are set out in Table I. These are presented in three groups: before operation, 
TABLE I

OVERALL INTELLIGENCE SCORES FOR 11 SURVIVING PATIENTS

\begin{tabular}{|c|c|c|c|c|c|c|c|c|c|c|c|c|c|}
\hline \multirow{3}{*}{ Patient } & \multirow{3}{*}{$\begin{array}{l}\text { Side } \\
\text { Removed }\end{array}$} & \multirow{3}{*}{$\begin{array}{l}\text { Length of } \\
\text { Follow-up } \\
\text { (yr.) }\end{array}$} & \multicolumn{3}{|l|}{ Age (yr.) at } & \multirow{2}{*}{\multicolumn{3}{|c|}{ Before Operation }} & \multirow{2}{*}{\multicolumn{3}{|c|}{ Early Post-operative }} & \multirow{2}{*}{\multicolumn{2}{|c|}{ Late Post-operative }} \\
\hline & & & Onset of & Onset of & Operation & & & & & & & & \\
\hline & & & & & & R.S.B. & $\boldsymbol{W} . \boldsymbol{V}$. & $W . P$. & R.S.B. & $W . V$. & $\boldsymbol{W . P .}$ & $\boldsymbol{W} . \boldsymbol{V}$. & W.P. \\
\hline $\begin{aligned} 1 & \text { P.G. } \\
3 & \text { J.H. } \\
5 & \text { M.N. } \\
6 & \text { D.W. } \\
8 & \text { R.le M. } \\
12 & \text { J.R. } \\
13 & \text { A.G. } \\
14 & \text { W.B. } \\
15 & \text { A.P. } \\
16 & \text { C.J. } \\
18 & \text { D.K. }\end{aligned}$ & $\begin{array}{l}\text { R. } \\
\text { R. } \\
\text { L. } \\
\text { L. } \\
\text { L. } \\
\text { L. } \\
\text { L. } \\
\text { L. } \\
\text { L. } \\
\text { L. } \\
\text { R. }\end{array}$ & $\begin{array}{l}15 \\
15 \\
14 \\
14 \\
13 \\
11 \\
10 \\
10 \\
10 \\
6 \\
4\end{array}$ & $\begin{array}{l}12 \\
<1 \\
9 \\
1 \\
3 \\
2 \\
1 \\
<1 \\
<1 \\
<1 \\
2\end{array}$ & $\begin{array}{l}10 \\
<1 \\
9 \\
6 \\
3 \\
1 \\
1 \\
<1 \\
7 \\
7 \\
3\end{array}$ & $\begin{array}{l}19 \\
7 \\
13 \\
20 \\
16 \\
5 \\
5 \\
4 \\
13 \\
11 \\
10\end{array}$ & $\begin{array}{l}128 \\
65 \\
55 \\
97 \\
48 \\
84 \\
39 \\
47 \\
54 \\
\\
73\end{array}$ & $\begin{array}{l}60 \\
75\end{array}$ & $\begin{array}{l}48 \\
55\end{array}$ & $\begin{array}{l}142 \\
73 \\
62 \\
100 \\
49 \\
83 \\
39 \\
53 \\
54 \\
55 \\
80\end{array}$ & $\begin{array}{l}118 \\
\left(71^{1}\right) \\
96 \\
(85)\end{array}$ & $\begin{array}{l}94 \\
(58) \\
114 \\
(72)\end{array}$ & $\begin{array}{l}121 \\
72 \\
64 \\
100 \\
70 \\
95 \\
45 \\
56 \\
78 \\
75 \\
71\end{array}$ & $\begin{array}{l}91 \\
63 \\
65 \\
101 \\
72 \\
77 \\
44 \\
50 \\
82 \\
55 \\
57\end{array}$ \\
\hline
\end{tabular}

R.S.B. $=$ Revised Stanford-Binet

W.V. = Wechsler verbal

W.P. $=$ Wechsler performance

${ }^{1}$ Figures in brackets indicate that the test figures were obtained outside the first year after operation.

in the first year after operation, and in 1965 respectively. Many of the patients were tested more frequently than this, but no test carried out less than two months after operation was used in order to avoid the influence of the physical effects of operation and the effect of being in hospital.

The overall results are clear. First, no patient capable of being tested has been made worse by the operation, and some have made worthwhile gains. In patient 8 this has been striking. This girl, 16 years old at operation, was a severe mental defective, confined to an institution, with a major aggressive behaviour disorder and frequent major convulsions. She improved from a Stanford-Binet I.Q. of less than 50 to a W.A.I.S. score of over 70 over the last 12 years, a complete change in category. With this has gone a radical improvement in behaviour so that she is now an agreeable and likeable young woman, living at home, able to read and earning money by craft work and benefiting by further training. The early post-operative score in this case showed no improvement. She has had no fits since the operation. In addition, patients $1,6,12,15$, and 16 have shown some improvement. Patients $3,5,13,14$, and 18 have not changed substantially, and patient 17 was too young to be assessed before operation.

In patient 15 testing had been carried out over long intervals before and after operation. The overall scores demonstrate a contrast between a drop in the measured intelligence over the five years before operation, when fits were very frequent and severe, and a rise in the 10 years free of fits after operation (Fig. 1).

In view of the increasing recognition that spatial orientation is a function of the right or non-dominant cerebral hemisphere, four male patients who were capable of being tested before and after operation on
Wechsler type tests were considered further. Standard scores on two tests, one each from the 'verbal' and 'performance' sides of the Wechsler tests, have been compared. The comprehension subtest has been chosen to represent 'verbal' or dominanto hemisphere (left) function and block design com prehension and to represent performance or non $\mathbb{D}$ dominant hemisphere (right) function. A simila manoeuvre has been adopted by Basser (1962). None of these patients was dysphasic or had a recognizable difficulty in speech or reading. In Figs. 1 and 2 the results are seen for the patients taken in pairs one of each pair having had the right hemisphere re을 moved, the other having had a left hemispherectomy?

In Fig. 2, the two most intelligent patients, both operated upon as adults, are compared. Each is working; patient 1, having obtained a university diploma after operation, has a responsible administrative position with a local authority and has no fits, while patient 6 has a semi-skilled manual job in a factory, and still has fits, although at a greatly reduced frequency. It is apparent that the emphasis is on retention of verbal skill by the left hemisphere, and of spatial ability by the right.

In Fig. 3 a similar situation is seen. The nonverbal skills of patient 15 , who had the left hemisphere removed, outweighs his verbal abilities, and the converse is true of patient 18 , with a right hemisphere removed. Both these patients were operated upon as children and both are free of fits. The verbal/spatial differences have become less obvious with the passage of time, but the trend is consistent through all four of these cases.

We examined the data from the other and less intelligent patients, but although possible trends conforming with the situation above were seen in the overall verbal and performance scores, no consistent 


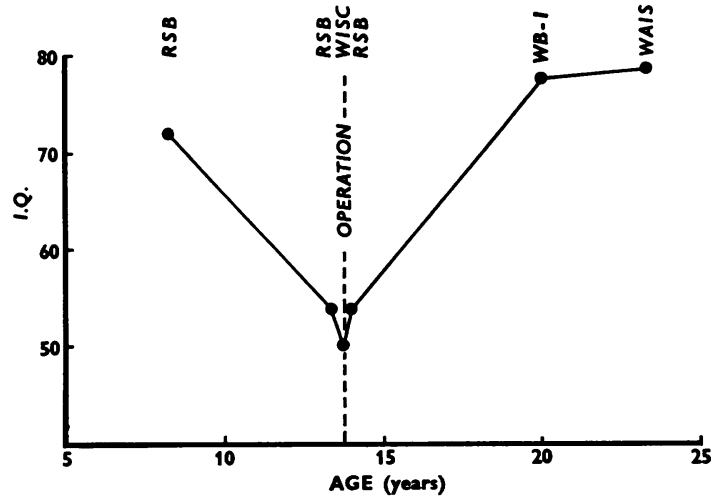

FIG. 1. Fall of I.Q. over five years before left hemispherectomy and rise over 10 years post-operatively. R.S.B. = Revised Stanford-Binet. W.I.S.C. = Wechsler intelligence scale for children. W.B.I. $=$ Wechsler-Bellevue form 1.W.A.I.S. = Wechsler adult intelligence scale (as in subsequent figures).

PATIENT 1. R. HEMISPHERECTOMY.

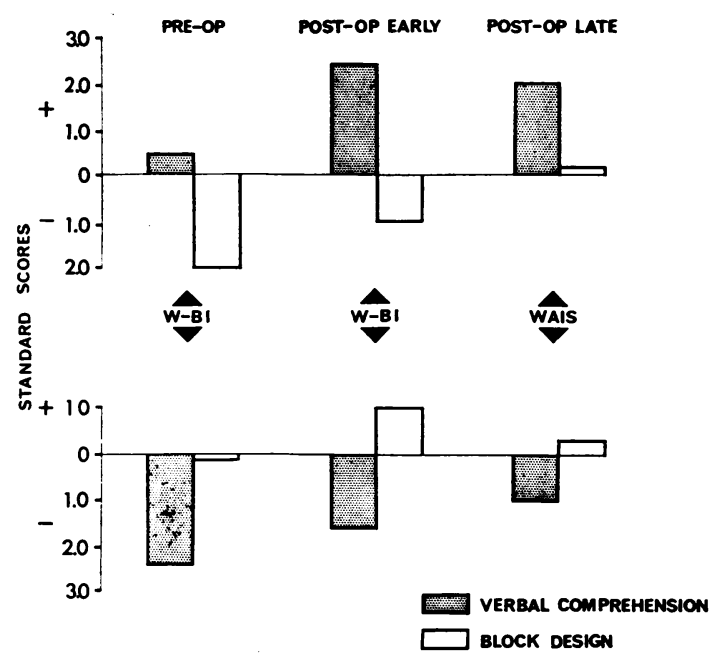

PATIENT 6. L. HemisPHERECTOMY.

FIG. 2. Comparison of the verbal and performance scores in the most intelligent two patients, both males, patient 1 (right hemispherectomy), and patient 6 (left hemispherectomy). (For key see legend to Fig. 1.)

pattern could be discerned. In patient 12 , a woman who had the left hemisphere removed, whose tested verbal capabilities taken in the gross outweighed her performance scores, this was largely due to a good score in arithmetic. Examination of the subtests revealed better scores on block design than on verbal comprehension. She has a strong family history of ambidexterity, and is said by her parents to have more of an aptitude for manual skills than for verbal ones. Thus the trend here too is in keeping with the right-left differences in the other more intelligent patients. The standardized scores on the two subtests for all the patients seen in 1965, tested under the same conditions by one of us, are given in Table II.

It can be seen that there is an overall tendency, more obvious in the more intelligent patients, for the verbal comprehension score to outstrip the block design score in those with right hemisphere lesions, and for the converse position in those who had the left hemisphere removed. In the exceptions there was no tendency to left-handedness in the parents

PATIENT 18, R. HEMISPHERECTOMY.
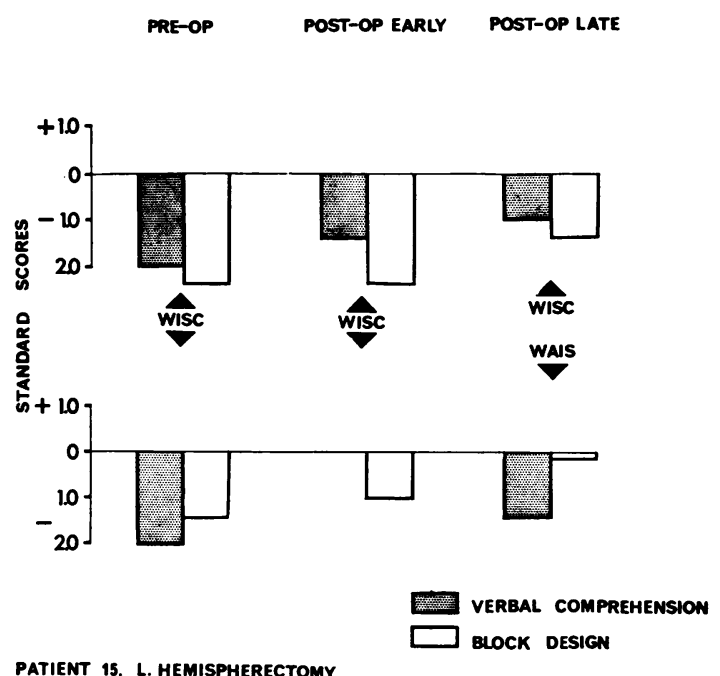

FIG. 3. Comparison of the verbal and performance scores in two younger male patients of low-average intelligence, with right hemispherectomy (patient 18) and left hemispherectomy (patient 15) respectively. (For key see legend to Fig. 1.)

TABLE II

LATE POST-OPERATIVE (1965) STANDARD SUBTEST SCORES

\begin{tabular}{llcc} 
Patient & Side Removed & Verbal Comprehension & Block Design \\
\hline 1 P.G. & R. & +2.8 & +0.3 \\
3 J.H. & R. & -1.5 & -1.2 \\
5 M.N. & L. & -2.4 & -1.2 \\
6 D.W. & L. & -1.0 & +0.6 \\
8 R.le M. & L. & -1.8 & -0.6 \\
12 J.R. & L. & -1.4 & +0.2 \\
13 A.G. & L. & -3.3 & -2.7 \\
14 W.B. & L. & -2.7 & -3.3 \\
15 A.P. & L. & -1.4 & 0 \\
16 C.J. & L. & -1.4 & -1.8 \\
17 D.G. & L. & -1.3 & -2.0 \\
18 D.K. & R. & -1.0 & -1.7
\end{tabular}


or in the sibs nor, as far as we could gather, in grandparents or uncles or aunts.

BEHAVIOUR The evidence here is necessarily more subjective, but there can be no doubt that no patient has had the behaviour disorder made worse, and some of the improvements have been gratifying, both to the patients and to their relatives. This can be easily seen in Table III.

\section{TABLE III}

CHANGES IN BEHAVIOUR RATING OPERATED BY OBSERVERS A AND B INDEPENDENTLY

Patient Pre-operative Early Post-operative Late Post-operative (1965)

\begin{tabular}{|c|c|c|c|c|c|c|}
\hline & $\boldsymbol{A}$ & $\boldsymbol{B}$ & $A$ & $B$ & $A$ & $B$ \\
\hline 1 P.G. & 2 & 1 & 1 & 1 & 0 & 0 \\
\hline 3 J.H. & 3 & 2 & 2 & 1 & 1 & 0 \\
\hline 5 M.N. & 3 & 3 & 3 & 3 & 2 & 2 \\
\hline 6 D.W. & 2 & 3 & 1 & 3 & 1 & 1 \\
\hline 8 R.leM. & 4 & 4 & 3 & 2 & 0 & $\mathbf{0}$ \\
\hline 12 J.R. & 3 & 1 & 2 & 1 & 1 & $\mathbf{0}$ \\
\hline 13 A.G. & & 3 & & 2 & & 1 \\
\hline 14 W.B. & 3 & 3 & 2 & 3 & 1 & 2 \\
\hline 15 A.P. & 3 & 3 & 2 & 2 & 1 & 1 \\
\hline 16 C.J. & & 3 & & 2 & & 2 \\
\hline 17 D.G. & & 0 & & 0 & & $\mathbf{0}$ \\
\hline 18 D.K. & 3 & 3 & 2 & 2 & 1 & 1 \\
\hline
\end{tabular}

On a more individual level the phrases used by the parents about these children have been revealing. 'The operation has made a new girl of her' (patient 16). 'It was just like a miracle really' (patient 15). And by a patient (8) about herself 'I am more contented with my life now than I have ever been'. Occasionally, of course, the parents' assessment is unrealistic, as in the case of patient 15 whose parents later denied the presence of any behaviour difficulty before the operation; there is in fact a mild, but improved, residual disturbance. No patient is in an institution because of behaviour difficulties, while three are in schools for the physically handicapped and another in a hostel for the physically handicapped.

The impression is that the duller patients have greater defects in the sphere of behaviour than those who are intellectually better preserved.

\section{DISCUSSION}

The difficulties in assessing these patients and of attributing the beneficial effects of the operation to its direct effect on brain physiology have been described by Howells and Kay (1951). In the sphere of behaviour there is little agreement as to what constitutes improvement. For instance, Munz and Tolor (1955) report a contraction of emotional response as a loss, whereas this could equally well be regarded as an improvement in a disturbed patient. However, as far as the effect on behaviour is concerned, White (1961) in his comprehensive review of the literature surrounding this operation, reports improvement in personality in $80 \%$ of 134 cases, $2 \%$ showing no improvement and one being made worse. In the remaining cases the results are uncertain. Subjective assessments were used throughout. Objective assessment of personality change has been attempted only by Uecker et al. (1954) but no remarkable changes were registered on either the Vineland scale or the M.M.P.I., on which their very retarded and institutionalized cases were assessed before and at a relatively short interval after operation. Although subjective gains in behaviour were noted, all remained in institutions. Abolition of fits does not seem to be necessarily connected with improvement in behaviour, although our sole patient having fits is the only one under surveillance by the law and by psychiatrists. Krynauw (1950) suggested that the removal of the abnormally firing hemisphere was the factor producing the improvement in behaviour after operation. Our data do not allow us to take this further except to confirm in the long termo the previously reported short-term gains in behavioup and ability to concentrate.

As far as intelligence is concerned, again fevo objective studies have been carried out. McKissock (1953) reported short-term improvement in 13 of 17 cases, one being worse and three unchangedo From the same hospital Basser (1962) reported sigs nificant improvement in verbal intelligence scores if a variety of tests after operation in five of 35 cases, with temporary deterioration in two, the remainder being unchanged. In his material there was no significant difference in the age-corrected scores of verbal intelligence between 48 cases of infantile hemiplegia with left hemisphere lesions and 54 cases with right hemisphere lesions, although the cases subjected to hemispherectomy are submerged in this material. No comparison of individual cases with the scores on the block-design test was made. Munz and Tolor (1955) found no overall gain in four very dull patients after operation. Rowe (1937) reported no change in the Stanford-Binet score (six months post-operatively) after right hemispherectomy for tumour.

Five of our 12 patients have made worthwhile gains in intelligence over the years. These include the most intelligent patients, and one previously regarded as a borderline imbecile.

There is no doubt that as a group infantile hemiplegics without epileptic fits possess much higher intelligence than those with fits (Perlstein and Hood, 1955; Crothers and Paine, 1959). There is also no doubt that in individuals bouts of status epilep- 
ticus can be associated with a marked deterioration in intellect, as in our patient 16 in the pre-operative period. In patients 15 (Fig. 1) and 18 very frequent fits were also associated with a progressive fall in the measurable I.Q. before operation. Abolition of the fits in these cases has been accompanied by a rise in the measurable intelligence to a very variable extent, patient 16 improving hardly at all, while the two others improved significantly. On the other hand patient 6 , whose fits were not stopped but only reduced in frequency, improved his scores significantly after operation. The impression is obtained that long-term improvement in intelligence is related more to the level of intelligence before operation, but only in a very rough and general way. As no other long-term studies of intelligence after hemispherectomy have appeared, it is not possible to be certain as to whether our patients have done as well as or better than those elsewhere in this respect.

There is a suspicion that both as individuals (Brandt, 1962) and as a group infantile hemiplegics fall further behind the normal as development takes place. More than twice as many patients of Crothers and Paine (1959) were at subsequent follow-up of lower intelligence than was originally estimated. Perlstein and Hood (1955) deny this, but their study was a cross-sectional one and does not take into account the tendency of the most handicapped to fall out and die in institutions, thus artificially raising the apparent intelligence of the remainder. It is encouraging that our surviving operated patients have maintained their intellectual development or improved it with the passage of time.

Interest in the spatial and constructional functions of the right or non-dominant hemisphere (e.g., McFie, Piercy, and Zangwill, 1950; Whitty and Newcombe, 1965) stimulated us to try to examine this aspect of our patients' mental capabilities. Although we have only four usefully analysable cases, the results suggest that transfer of hemisphere function to the other side is a process which sometimes, even in the very young, falls short of completion. With the passage of time their verbal-spatial disparity may become less, but remains more easily detectable in the more intelligent patients. As an explanation there may be other complicating factors at work; for instance, it is well known that patients with a left homonymous hemianopia experience more difficulty in the mechanical aspects of reading than those with a right homonymous defect. On the other hand Perlstein and Hood (1955) recognize that . . . . the motor handicap of the hemiplegic is practically never great enough to vitiate testing procedures . . . . Our material is not adequate to take this observation further, but it should be enough to stimulate re-examination of the widely accepted view that after a catastrophe in early life transfer of intellectual function to the other hemisphere is complete. It is demonstrably incomplete for motor and sensory functions, and for a similar state of affairs to exist for other aspects of brain function would not be at all surprising. If our suspicion of the existence of a lasting handicap, variable as to the side involved, is well founded it is of interest to consider in what practical way this could influence these patients' adjustment. It seems to us that the less intelligent patients, who will be largely concerned by their education and future employment with practical and non-verbal skills, would be better off with a left hemisphere lesion than with a lesion on the other side. Correspondingly an intelligent hemiplegic would seem to be better off with a left hemiplegia, as the acquisition of verbal skills would enable him best to circumvent his physical handicap. In view of the practical consequences of differences of this kind, confirmation of our view would be of some importance.

\section{SUMMARY}

Studies of intelligence and behaviour were made before and after hemispherectomy for infantile hemiplegia and repeated in 12 surviving patients at an interval after operation averaging over 10 years.

There were worthwhile and significant long-term gains in intelligence in five of 12 patients, while six patients showed slight but insignificant gains. No patient lost ground as a result of operation.

Changes in behaviour were subjectively striking and have been maintained over the years.

Observations are made which indicate that after infantile hemiplegia, even in early life, transfer of intellectual faculty from one hemisphere to another may be incomplete, as it is for somatic functions. Possible practical implications of this theory are discussed.

Our thanks are due to Mr. Joe Pennybacker and to $\mathrm{Mr}$. Walpole Lewin for permission and encouragement to study their cases. The patients themselves, as well as the present investigators, owe a great deal to Elizabeth Turner and Francesca Ward, of the Department of Medical Social Work, without whose efforts their study would have been impossible.

\section{REFERENCES}

Basser, L. S. (1962). The effects of hemispherectomy on speech. Brain, 85, 427-460.

Brandt, S. (1962). Causes and pathogenic mechanisms of acute hemiplegia in childhood. Little Club Clinics in Developmental Medicine, 6, 7-11.

Cairns, H., and Davidson, M. A. (1951). Hemispherectomy in the treatment of infantile hemiplegia. Lancet, 2, 411-415. 
Crothers, B., and Paine, R. S. (1959). The Natural History of Cerebral Palsy. Oxford University Press, London.

Howells, J. G., and Kay, E. I. (1951). Cerebral hemispherectomy. Lancet, 2, 683.

Krynauw, R. A. (1950). Infantile hemiplegia treated by removing one cerebral hemisphere. J. Neurol. Neurosurg. Psychiat., 13, 243-267.

McFie, J., Piercy, M. F., and Zangwill, O. L. (1950). Visual-spatial agnosia associated with lesions of the right cerebral hemisphere Brain, 73, 167-190.

McKissock, W. (1953). Infantile hemiplegia. Proc. roy. Soc. Med., 46, 431-434.

Munz, A., and Tolor, A. (1955). Psychological effects of major cerebral excision: intellectual and emotional changes following hemispherectomy. J. nerv. ment. Dis., 121, 438-443.
Oppenheimer, D. R., and Griffith, H. B. (1966). Persistent intracranial bleeding as a complication of hemispherectomy. J. Neurol. Neurosurg. Psychiat., 29, 229-240.

Perlstein, M. A., and Hood, P. N. (1955). Infantile spastic hemiplegia. III. Intelligence. Pediatrics, 15, 676-682.

Rowe, S. N. (1937). Mental changes following the removal of the right cerebral hemisphere for brain tumour. Amer. J. Psychiat. 96, 605-612.

Uecker, A. E., French, L. A., and Johnson, D. R. (1954). Psychological studies of seven epileptic hemiparetics before and after hemispherectomy. Arch. Neurol. Psychiat. (Chic.), 72, 555-564.

White, H. H. (1961). Cerebral hemispherectomy in the treatment of infantile hemiplegia. Confin. neurol. (Basel), 21, 1-50.

Whitty, C. W. M., and Newcombe, F. (1965). Disabilities associated with lesions in the posterior parietal region of the non-dominant hemisphere. Neuropsychologia, 3, 175-185. 